\title{
PENERAPAN KONSEP LIBRARY CAFE DI THE READING ROOM JAKARTA
}

\author{
Ghafeera Safiyya ${ }^{1}$, Rohanda $^{2}$, Nuning Kurniasih ${ }^{3}$ \\ ${ }^{1}$ Gagas Media, ${ }^{2,3}$ Program Studi Ilmu Perpustakaan Universitas Padjadjaran \\ 1' ghafeera35@gmail.com, ${ }^{2}$ rohanda@unpad.ac.id, ${ }^{3}$ nuningkurniasih@yahoo.com
}

\begin{abstract}
This research is about to understanding the role of a library concept "The Reading Room". The primary purpose of this research is to determine the extend to which room comfort, cafeteria, facility, and book collection play a significant role to enchance one's motivation to read. The chosen method to carry out this research is using a survey method of variable list that we have chosen to be an important factor. In addition, the data collection method we have chosen consist of two sources. The primary data is taken from a survey with 60 people of respondent, and the secondary data is obtained by conducting interview with the owners and managers of the location itself, fields observation and library research. From the result of this research, we can confidently conclude that room comfort, cafeteria, facility and book collection have proven to be a good factor to which support the interesting of people to read.
\end{abstract}

Keyword: Library, Library Cafe, Reading Interests.

ABSTRAK - Penelitian ini mengenai peran penerapan konsep library cafe di The Reading Room dalam menunjang minat baca. Tujuan dari penelitian ini adalah untuk mengetahui sejauh mana peranan kenyamanan ruang, fasilitas, layanan kafetaria, dan koleksi yang tersedia di The Reading Room dalam menunjang minat baca. Metode penelitian yang digunakan adalah survei yang dimaksudkan untuk menggambarkan atau memaparkan variabel-variabel yang menjadi objek penelitian. Teknik pengambilan data yang digunakan dalam penelitian ini berasal dari dua sumber, yaitu data primer yang diperoleh melalui angket dengan jumlah responden 60 orang, dan data sekunder yang diperoleh melalui wawancara dengan pemilik serta pengelola The Reading Room, observasi di lapangan, serta studi kepustakaan. Hasil penelitian ini menyatakan bahwa pengunjung The Reading Room menilai kenyamanan ruang, fasilitas, kafetaria, dan koleksi yang tersedia di library cafe The Reading Room sudah cukup baik dalam menunjang minat baca.

Kata kunci: Perpustakaan, Perpustakaan Kafe, Minat Baca.

\section{PENDAHULUAN}

Sejatinya perpustakaan merupakan sebuah tempat yang menyediakan segala macam informasi dan ilmu pengetahuan. Perpustakaan juga menjadi tempat yang menyenangkan bagi mereka yang gemar membaca. Namun, berdasarkan fenomena yang terlihat saat ini terdapat golongan anak muda yang konsumtif dengan mengisi waktu luangnya seperti pergi ke mall atau nongkrong dari pada datang ke perpustakaan untuk menambah wawasan dan pengetahuan. Berdasarkan hasil jejak pendapat tentang minat baca yang pernah dilakukan Kompas (14/2/2009) dari total responden yang dicuplik secara sistematis di beberapa kota besar seperti Kota Semarang, Solo, Purwokerto, dan Tegal: 75,5 persen mengaku tidak pernah berkunjung ke perpustakaan dalam sebulan terakhir (Fatmawati 2010, i).

Upaya kreatif penggabungan konsep perpustakaan dan cafe bertujuan untuk tetap mengeksiskan perpustakaan di tengah-tengah masyarakat. Selain membangun sebuah citra baru perpustakaan, konsep perpustakaan dengan kafe ini diharapkan mampu menunjang masyarakat mendapatkan komposisi yang seimbang antara hiburan dan edukasi. Saat ini sudah ada beberapa library cafe di kota Jakarta dan Bandung diantaranya yaitu ZOE Cafe \& Library, Kineruku, Potluck Coffee Bar \& Library, Comic Cafe, dan The Reading Room. 
The Reading Room "Books Lounge and Screening" merupakan salah satu library cafe yang bertempat di daerah Kemang, Jakarta Selatan. Reading Room yang telah dibuat sejak tahun 2011 ini dibangun oleh Richard $\mathrm{Oh}$, seorang penulis novel, filmmaker, dan owner toko buku Quality Buyer di tahun 1999-2006. Mengusung konsep library cafe, Reading Room menyajikan sebuah tempat dimana pengunjung yang datang bisa membaca buku, mencari bahan research, ataupun hanya sekedar saling bertukar pikiran. Dilengkapi dengan desain interior modern dan ruangan yang bersih memberikan suasana yang nyaman untuk membaca. Suhu ruangan yang sejuk, dinding berwarna hijau dan kuning memberikan kesan yang cerah dan fresh berada di Reading Room. Dipenuhi dengan rak buku kayu tinggi yang memenuhi dinding dan ruangan menjadikan tempat ini sangat dijiwai oleh buku.

Koleksi yang dimiliki Reading Room mencapai 3000 buku, berasal dari koleksi pribadi Bapak Richard Oh dan buku-buku sisa dari gerai toko buku Quality Buyer. Koleksi buku yang ditawarkan Reading Room merupakan buku-buku lokal dan import, didominasi oleh novel dan buku fiksi yang unik dan jarang kita temui di toko buku. Untuk koleksi buku ilmiah diletakkan pada satu rak khusus yang dinamakan "Private Collection", menawarkan buku-buku yang lebih bervariasi, mulai dari filsafat, sejarah, sastra, puisi, biografi, dan natural scince. Buku-buku yang ditawarkan Reading Room dapat kita baca gratis, tetapi tidak untuk dibawa pulang atau dipinjamkan. Untuk meminjam koleksi "Private Collection" ada sistem peminjaman tersendiri, yaitu dengan menitipkan
KTP atau identitas lainnya selama membaca di Reading Room.

Reading Room dengan konsep library cafe menciptakan suasana baru perpustakaan yang lebih fleksibel dan santai. Menjangkau masyarakat sebanyak-banyaknya untuk dapat menikmati buku-buku secara gratis. Menghadirkan sebuah tempat yang nyaman untuk membaca, untuk mengeksplor buku bacaan hiburan dan ilmiah, atau hanya sekedar untuk saling bertukar pikiran dengan rekan kita. Dibangunnya Reading Room ini diharapkan masyarakat dapat menikmati nuansa baru perpustakaan dan menunjang kegiatan membaca buku di perpustakaan. Dari mulai menggemari membaca buku ringan atau fiksi, akan menjadi gerbang untuk mengembangkan minat baca.

\section{TINJAUAN PUSTAKA}

Melihat kondisi harga buku yang tidak murah dan tidak semua kalangan dapat mengakses $e$-book, seharusnya masyarakat bisa memanfaatkan perpustakaan umum untuk mendapatakan buku dengan mudah. Rendahnya intensitas masyarakat mengunjungi perpustakaan menjadi takaran kurangnya pula minat membaca di perpustakaan.

"Dari beberapa temuan di lapangan, keengganan datang ke pepustakaan ternyata lebih banyak disebabkan oleh kurang menariknya perpustakaan, sikap pustakawan yang kurang bersahabat, dan fasilitas serta koleksi yang terbatas" (Fatmawati 2010, ii). Kurangnya pengelolaan dan pengembangan yang maksimal membuat perpustakaan kurang menarik perhatian masyarakat. Sebuah perpustakaan seharusnya turut aktif dalam mengembangkan inovasi-inovasi baru. 
Kini saatnya perpustakaan mengubah konsep yang terkesan scientific (ilmiah) ke konsep yang lebih menonjolkan kesan rekreatif atau hiburan untuk bisa menumbuhkan rasa senang bagi pengunjungnya. "Konsep perpustakaan rekreatif maksudnya bahwa orang ke perpustakaan tidak hanya untuk mencari buku kemudian meminjam lalu mengembalikan, namun juga bisa datang ke perpustakaan untuk sekedar melepaskan penat" (Fatmawati 2010, 19). Sebagai pustakawan yang profesional, paling tidak harus mampu memberikan gebrakan baru untuk perpustakaan dan taman bacaan yang modern agar masyarakat menyukai kegiatan membaca di perpustakaan.

Library cafe atau perpustakaan kafe merupakan salah satu inovasi perpustakaan yang telah hadir beberapa tahun belakangan ini. Konsep libarary cafe adalah perpustakaan yang sangat fleksibel dan didesain sesantai mungkin dengan kombinasi cafe di dalamnya (Maulana, 2015). Dengan menggabungkan kedua konsep tersebut dapat menarik perhatian masyarakat untuk berkunjung ke perpustakaan.

Selain didirikan untuk profit oriented dengan menjual produk makanan dan minuman, yang menjadi tujuan utama penggabungan dua konsep ini ialah untuk ikut membantu mencerdaskan kehidupan bangsa dengan membaca (Maulana, 2015).

\section{METODE PENELITIAN}

Metode penelitian yang digunakan dalam penelitian ini adalah metode survai. Metode yang digunakan untuk mendeskripsikan mengenai bagaimana peranan konsep library cafe dalam menunjang minat membaca melalui data. Menurut
Sugiyono $(2011,6)$ mengungkapkan bahwa metode survei digunakan untuk mendapatkan data dari tempat tertentu yang alamiah, tetapi peneliti melakukan perlakuan dalam pengumpulan data, misalnya dengan mengedarkan kuesioner, test, wawancara terstruktur dan sebagainya.

\section{HASIL DAN PEMBAHASAN}

\section{Peran Kenyamanan Ruang}

Tabel 1

Kategori Kenyamanan Ruang

\begin{tabular}{|l|l|l|l|}
\hline No. & Kategori & Frekuensi & Persentase \\
\hline 1 & Rendah & 0 & 0 \\
\hline 2 & Sedang & 12 & 20 \\
\hline 3 & Tinggi & 48 & 80 \\
\hline \multicolumn{2}{|l|}{ Total } & 60 & 100 \\
\hline
\end{tabular}

Sumber: Pengolahan data 2015

Tabel 1 memperlihatkan konsep library café dilihat dari subvariabel kenyamanan ruang (X1). Pada tabel diketahui bahwa hampir seluruhnya $(80 \%)$ dari responden memberikan respon jawaban tinggi sebanyak 48 orang. Sedangkan sebagian kecil (20\%) dari responden memberikan respon jawaban sedang sebanyak 12 orang, dari jumlah keseluruhan 60 orang responden penelitian.

Kenyamanan sebuah perpustakaan dapat diukur dari berbagai aspek yang dimiliki oleh perpustakaan tersebut, apakah fasilitas, sumber daya manusia ataukah ketersediaan koleksi yang dimilikinya. Perpustakaan modern masa kini tentunya harus memenuhi kriteria tersebut agar dapat disebut sebagai sebuah perpustakaan yang nyaman, selain itu juga perpustakaan masa kini harus memiliki keunikan tersendiri yang berfungsi sebagai daya tarik. Daya tarik sebuah perpustakaan 
masa kini bukan hanya dari ketersediaan jumlah koleksi yang dimilikinya, tetapi juga dari tampilan dan berbagai hal yang dimiliki untuk ditawarkan pada para pemustakanya.

Berdasarkan data mengenai kenyamanan ruang pada Reading Room ruangan terdapat pada kategori tinggi. Diperoleh dari hasil responden 62\% menyatakan setuju mengenai kesejukan udara, 56\% responden menyatakan setuju mengenai kebersihan ruangan, $61 \%$ responen menyatakan setuju mengenai kenyamanan ruangan, dan 56\% responden menyatakan setuju bahwa pemutaran musik diruangan tidak mengganggu kenyamanan. Artinya mayoritas responden merasa nyaman untuk berada di Reading Room terlepas dari kegiatan apa saja yang menjadi tujuannya. Kenyamanan ruangan Reading Room diukur dari kesejukan udara, kebersihan, ketenangan, kenyamanan dan keberadaan pemutaran musik pada ruangan. Sebuah tempat atau ruangan yang dapat memberikan kenyamanan bagi seseorang tentunya akan dapat memberikan sebuah inspirasi atau sebuah ide gagasan baru yang segar.

\section{Peranan Fasilitas}

Tabel 2

Kategori Fasilitas

\begin{tabular}{|l|l|l|l|}
\hline No. & Kategori & Frekuensi & Persentase \\
\hline 1 & Rendah & 0 & 0 \\
\hline 2 & Sedang & 17 & 28,3 \\
\hline 3 & Tinggi & 43 & 71,7 \\
\hline \multicolumn{2}{|l}{ Total } & 60 & 100 \\
\hline
\end{tabular}

Sumber: Pengolahan data 2015

Tabel 2 memperlihatkan konsep library cafe dilihat dari subvariabel fasilitas (X2). Pada tabel diketahui bahwa lebih dari setengahnya $(71,7 \%)$ dari responden memberikan respon jawaban tinggi sebanyak 43 orang. Sedangkan hampir setengahnya $(28,3 \%)$ dari responden memberikan respon jawaban sedang sebanyak 17 orang, dari jumlah keseluruhan 60 orang responden penelitian.

Fasilitassebuah perpustakaan tentunya harus sangat diperhatikan, karena tidak hanya ketersediaan koeksi yang menjadi daya tarik sebuah perpustakaan. Ketersediaan berbagai fasilitas yang memadai tentunya akan sangat membantu para pengguna perpustakaan dalam melakukan beragam kegiatannya ketika berada dalam sebuah perpustakaan.

Sudah lumrah rasanya pada sebuah perpustakaan dilengkapi dengan pengtur suhu ruangan seperti AC atau kipas angin, bahkan sampai tersedianya koneksi internet nirkabel (Wi-fi). Fasilitas yang dapat menunjang berbagai kegiatan pengunjung perpustakaan inilah yang akan membuat pemustaka merasakan nyaman atau tidak. Menurut Maulana (2010) dari keempat elemen library café tentunya fasilitas menjadi salah satu hal yang dapat menunjang kegiatan perpusakaan:

Jadikan library cafe yang dikelola memiliki fasilitas yang lengkap. Perhatikan hal-hal detail yang sering terlupakan tetapi penting, seperti tersedianya terminal listrik yang cukup bagi pengunjung yang ingin mengisi ulang baterai gadget-nya. Tidak ada salahnya jika dilengkapi dengan koneksi internet nirkabel (Wi-fi), karena dapat menunjang kebutuhan pengunjung yang datang untuk mengerjakan tugas.

Berdasarkan data mengenai fasilitas yang tersedia di Reading Room, terdapat pada kategori tinggi. Diperoleh dari hasil responden sebanyak 
$48 \%$ menyatakan setuju mengenai kelengkapan fasilitas, $60 \%$ responden menyatakan setuju mengenai kualitas fasilitas, $63 \%$ responden menyatakan setuju mengenai keterjangkauan fasilitas, dan $58 \%$ responden menyatakan setuju bahwa fasilitas tertata dengan rapih. Artinya mayoritas responden merasa fasilitas yang tersedia di Reading Room dapat menunjang berbagai kegiatan mereka terlepas dari tujuan kunjungan ke perpustakaan yang mengusung konsep library cafe ini. Fasilitas yang disediakan Reading Room diukur dari kelengkapan, keterawatan, keterjangkauan, kerapihan dan keteraturan serta kenyamanan yang diberikan. Perpustakaan dengan kepemilikan fasilitas yang dapat dibilang lengkap dan memadai tentunya akan memberikan rasa nyaman secara otomatis pada para pengunjungnya, hal ini tentunya harus sangat diperhatikan walaupun ini merupakan hal kecil yang terkadang terlewatkan.

\section{Peranan Kafetaria}

Tabel 3

Kategori Kafetaria

\begin{tabular}{|l|l|l|l|}
\hline No. & Kategori & Frekuensi & Persentase \\
\hline 1 & Rendah & 0 & 0 \\
\hline 2 & Sedang & 23 & 38,3 \\
\hline 3 & Tinggi & 37 & 61,7 \\
\hline \multicolumn{2}{|l|}{ Total } & 60 & 100 \\
\hline
\end{tabular}

Tabel 3 memperlihatkan konsep library cafe dilihat dari subvariabel ketersediaan kafetaria (X3). Pada tabel diketahui bahwa lebih dari setengahnya $(61,7 \%)$ dari responden memberikan respon jawaban tinggi sebanyak 37 orang. Sedangkan hampir setengahnya $(38,3 \%)$ dari responden memberikan respon jawaban sedang sebanyak 23 orang, dari jumlah keseluruhan 60 orang responden penelitian.

Kafetaria pada perpustakaan sebenarnya sudah banyak diaplikasikan baik pada perpustakaan konfensional maupun perpustakaan modern masa kini. Kehadiran perpustakaan dengan konsep kafe ini tentunya jauh dari image menyeramkan, monoton dan menyeramkan. Seperti yang kita ketahui bahwa kafe adalah sebuah tempat yang biasanya digunakan untuk bersantai dengan suasana nyaman yang jarang diperoleh di rumah tinggal pribadi, dengan ditemani alunan music atau bercanda dengan rekan-rean sejawat. Sedangkan perpustakaan merupakan sebuah tempat yang menyimppan berbagai ilmu yang dikemas dalam sebuah buku yang tertata rapi dan sesuai aturan. Bila digabungkan maka akan menjadi sebuah tempat yang menyenangkan, tempat membaca buku yang dapat membuat kita santai dengan suasana yang diberikan.

Dalam pengelolaannya terdapat beberapa sistem dan kebijakan pada perpustakaan yang mengusung konsep library cafe: 1) Mempebolehkan pengguna makan dan minum di perpustakaan, 2) Jam operasional yang lebih lama, 3) Layanan terbuka, artinya pengunjung dapat memilih sendiri buku-buku atau koleksi lainnya yang telah disediakan, 4) Biasanya juga menyediakan koleksi-koleksi yang dijual untuk pengguna, 5) Menyediakan layanan audiovisual seperti televisi, pemutaran film, musik, dan lain sebagainya.

Berdasarkan data mengenai kefetaria yang dimiliki Reading Room, terdapat pada kategori tinggi. Diperoleh dari hasil responden sebanyak 
48\% menyatakan setuju mengenai keberagaman menu, 50\% responden menyatakan setuju mengenai kesesuaian selera makanan, $41 \%$ responden menyatakan setuju mengenai kelezatan citarasa makanan, 58\% responden menyatakan setuju bahwa penyajian makanan cepat disajikan, dan 53\% menyatakan setuju bahwa kafetaria menjadi daya tarik dari Reading Room. Artinya mayoritas responden menyatakan bahwa mereka puas dengan menu yang dimiliki oleh kafe yang terdapat di Reading Room. Kafetaria Reading Room diukur dari keberagaman menu, kesesuaian selera, kelezatan rasa, kecepatan penyajian, dan kehadiran kefe yang menjadi daya tarik Reading Room.

Perpustakaan dengan konsep modern tentunya akan menyesuaikan diri dengan keadaan masyarakat masa kini yang memerlukan banyak hiburan untuk dapat mengisi waktu luangnya karena kejenuhan dalam kesehariannya. Konsep perpustakaan library cafe memberikan udara segar dalam dunia hiburan dan perpustakaan yang dapat menggabungkan segi positif yang dimiliki oleh keduanya.

\section{Peranan Koleksi}

Tabel 4

Kategori Koleksi

\begin{tabular}{|l|l|l|l|}
\hline No. & Kategori & Frekuensi & Persentase \\
\hline 1 & Rendah & 1 & 1,7 \\
\hline 2 & Sedang & 41 & 68,3 \\
\hline 3 & Tinggi & 18 & 30 \\
\hline & Total & 60 & 100 \\
\hline
\end{tabular}

Sumber: Pengolahan data 2015

Tabel 4 memperlihatkan konsep library cafe dilihat dari subvariabel koleksi (X4). Pada tabel diketahui bahwa lebih dari setengahnya $(68,3 \%)$ dari responden memberikan respon jawaban sedang sebanyak 41 orang. Sedangkan hampir setengahnya (30\%) dari responden memberikan respon jawaban tinggi sebanyak 18 orang, dan sebagian kecil $(1,7 \%)$ dari responden memberikan respon jawaban rendah sebanyak 1 orang, dari jumlah keseluruhan 60 orang responden penelitian.

Koleksi perpustakaan adalah semua informasi dalam bentuk karya tulis, karya cetak, dan/atau karya rekam dalam berbagai media yang mempunyai nilai pendidikan, yang dihimpun, diolah, dan dilayankan (UU RI No. 43 Tahun 2007). Koleksi yang baik adalah yang dapat memenuhi selera keinginan dan kebutuhan pada pembaca. Disini perpustakaan berfungsi sebagai jembatan perantara antara sumber informasi dengan masyarakat pengguna. Oleh sebab itu perpustakaan perlu memiliki bahan pustaka yang relatif lengkap sesuai dengan visi misi perencanaan strategi kebijakan dan tujuan nya.

Koleksi bahan pustaka yang memadai baik mengenai jumlah, jenis, dan mutunya yang terususun rapi dengan sistem pengolahan serta kemudahan akses atau temu kembali informasi merupakan salah satu kunci keberhasilan perpustakaan (Nusantari, 2012: 121). Kekuatan koleksi bahan pustaka merupakan daya tarik bagi pemakai sehingga semakin banyak dan lengkap koleksi bahan pustaka yang dibaca dan dipinjam akan semakin ramai perpustakaan yang dikunjungi masyarakat (Suwarno, 2009: 104).

Berdasarkan data mengenai koleksi buku yang dimiliki Reading Room Diperoleh dari hasil responden sebanyak $48 \%$ menyatakan setuju 
mengenai kelengkapan koleksi, 41\% responden menyatakan setuju mengenai relevansi koleksi, $63 \%$ responden menyatakan setuju bahwa buku yang tersedia terawat dengan baik, $50 \%$ responden menyatakan setuju bahwa koleksi yang tersedia menarik untuk dibaca, dan $36 \%$ responden menyatakan netral bahwa koleksi yang tersedia sudah up-to-date. Artinya mayoritas responden merasa ketersediaan koleksi yang dimiliki oleh Reading Room baik dalam pemenuhan informasi maupun hiburan mereka sudah cukup memuaskan. Koleksi yang disediakan oleh Reading Room diukur dari kelengkapan dan keberagaman, kerelevanan, keterawatan, kemenarikan isi dan ke up-to-datean koleksi. Koleksi yang dimiliki oleh Reading Room merupakan koleksi pribadi pemilik library café ini maka buku yang disediakan didominasi oleh buku-buku yang digemari oleh pemilik perpustakaan.

\section{SIMPULAN}

Peran ruangan library cafe di The Reading Room secara keseluruhan dapat memberikan kenyamanan bagi pengunjung. Ini didukung oleh kesejukan udara, kebersihan ruangan, dan ketenangan ruangan di Reading Room. Kenyamanan ruang Reading Room sudah cukup mampu menumbuhkan rasa senang melakukan kegiatan membaca di Reading Room. Peranan fasilitas penunjang library cafe di The Reading Room secara keseluruhan cukup mampu mendukung berbagai kegiatan yang dapat dilakukan di Reading Room. Didukung oleh kelengkapan, kualitas, dan kenyamanan fasilitas yang tersedia dianggap bermanfaat untuk menunjang kegiatan di Reading Room. Dengan fasilitas yang beragam seperti free wi-fi, stop kontak, dan screaning room Reading Room menghadirkan berbagai macam kegiatan lain yang dapat dilakukan pengunjung selain membaca. Peranan kafetaria yang tersedia di library cafe di The Reading Room secara keseluruhan dapat memberikan kepuasan terhadap citarasa dan penyajian makanan bagi pengunjung. Didukung oleh citarasa makanan, ragam menu pilihan dan pelayanan cepat saji yang dimiliki Reading Room. Dengan kata lain kafetaria Reading Room dapat menjadi daya tarik pengunjung untuk bisa membaca tanpa merasa lapar dan haus. Peranan koleksi yang tersedia di library cafe di The Reading Room dalam memberikan bacaan hiburan dan informasi ilmiah sudah cukup beragam, terawat, dan menarik penggunanya. Namun masih terbatas dalam pemenuhan informasi dan hibutan bagi penggunanya. Sehingga dengan kata lain ketersediaan koleksi di Reading Room masih kurang mencukupi kepuasan pengunjung dalam pemenuhan informasi dan hiburan.

\section{DAFTAR PUSTAKA}

Arikunto, Suharsimi. (1998). Prosedur Penelitian Suatu Pendekatan Praktek. Jakarta: Rineka Cipta

Bungin, Burhan. (2005). Metode Penelitian Kuantitatif : Komunikasi, Ekonomi, dan Kebijakan Publik serta Ilmu-Ilmu Sosial Lainnya. Ed. 1. Jakarta : Kencana

Bushman, John E. (2007). The Library as Place : History, Community, and Culture. Westport: Libraries Unlimited

Ching D.K.. (1996). Arsitektur, Bentuk, Ruang dan Tatanan. Jakarta: Erlangga. 
Depdikbud. (1994). Perpustakaan Perguruan

Tinggi: buku pedoman. Jakarta: Direktorat Jenderal Pendidikan Tinggi.

Fatmawati, Endang. (2011). The Art of Library.

Semarang: Badan Penerbit Universitas Diponegoro Semarang

Fatmawati, Endang. (2014). Rekonstruksi Peran Pustakawan Perguruan Tinggi Untuk Membangun Perpustakaan Ideal. Juara 1 Lomba Artikel Pustakawan Se-Jawa Tengah dan Daerah Istimewa Jogjakarta. Semarang: Universitas Dipenogoro. http://pustaka.uns.ac.id/?opt=1001\&menu=ne ws\&option =detail\&nid=411 (diakses pada tangal 25 September 2015).

Hermawan, Agus. (2012). Komunikasi Pemasaran. Jakarta: Erlangga.

Hernowo. (2002). Quantum Reading: cara cepat nan bermanfaat untuk merangsang munculnya potensi mambaca. Bandung: MLC.

Irkham, Agus M. (2010). The Art Of Library. http://radiobuku.com/2010/12/the-art-of-librar y/

Knoers, Monks dan Rahayu Haditomo. (1998). Psikologi Perkembangan. Yogyakarta: Gadjah Mada University Press.

Kohar, Ade. (2003). Teknik Menyusun Kebijakan Pengembangan Koleksi Perpustakaan. Jakarta: Pustakawan Madya-PDII LIPI.

Lasa, Hs. (2005). Manajemen Perpustakaan. Yogyakarta: Gama Media.

McQuail, Dennis. (1987). Teori Komunikasi Massa. Jakarta: Erlangga.

Murrison, William John. (1988). The Public Library: Its Origins, Purpose, and
Significance. 3rd ed. London: Clive Bingley Limited

Nusantari, Anita. (2012). Strategi Pengembangan Perpustakaan. Jakarta: Prestasi Pustaka.

Sugiyono. (2011). Metode Penelitian Pendidikan. Bandung: Alfabeta

Suwarno, Wiji. (2009). Psikologi Perpustakaan. Jakarta: Agung Seto 